\title{
ADDITIVE DECOMPOSITION AND BOUNDARY CONDITIONS IN WAVELET-BASED FORECASTING APPROACHES
}

\author{
Milan Bašta*
}

\section{Introduction}

Wavelet analysis is a favourite tool used for the description of time series, see e.g., Grinsted et al. (2004), Cornish et al. (2006), Ramsey and Zhang (1997), etc. In these papers, the use of the wavelet transform enables researchers to perceive the dynamics of time series as a function of scale and time. The scale can be informally considered proportional to the reciprocal of frequency, with short scales being associated with abrupt and fast changes and large scales with slow and trending motions.

A step which follows the description of time series is to build wavelet-based time series models. In a class of such models, the dynamics of the input time series is explicitly modelled as a sum of several contributions, each associated with a different scale. Consequently, these models have been used for providing a better forecast of the input time series; see, e.g., Renaud et al. (2005), Yousefi et al. (2005), Wong et al. (2003), Conejo et al. (2005) or Soltani (2002) (more details on these publications are provided below).

Since there are several variations on how wavelets can be used to facilitate time series forecasting, we have to be explicit about the general forecasting framework (which we will consider in this paper), hereafter called the "wavelet-based forecasting approach":

1. An input time series is decomposed into several components, each associated with a different frequency band. The decomposition is to be additive and based on some type of wavelet transform.

2. The dynamics of each component is modelled separately and the parameters of each model are (usually) estimated separately. Then the components are extrapolated (forecasted).

3. In the end, the forecasts of individual components are summed up to construct the forecast of the input time series.

* Faculty of Informatics and Statistics, University of Economics in Prague (milan.basta@vse.cz). This paper was written with the support of the Czech Science Foundation (GA CR), grant no. P402/12/P507, Modelling of Financial and Economic Time Series - Application and Comparison of Wavelet and Traditional Methods. 
As will be presented below, handling of so-called boundary conditions is of considerable importance in the practical implementation of the wavelet-based forecasting approach. However, these boundary conditions are not always handled properly in the literature. Since the interest in wavelet-based forecasting approaches has been growing recently in economic and financial fields, the goal of the paper is to present facts concerning boundary conditions, their proper handling and the additive nature of the decomposition in an intuitive and illustrative manner that can be easily understood.

It is important to note that the wavelet-based forecasting approach outlined above consists of several steps. The aim of this paper is to discuss the initial yet essential steps in this approach, the nature of the additive decomposition and correct handling of boundary conditions in particular. We do not tackle the other parts of this broad issue since that would go beyond the scope and extent of this paper.

The paper is structured as follows. In Section 2, we present some examples of wavelet-based forecasting models available in the literature, placing emphasis on the way in which the boundary conditions have been handled. In Section 3, the concept of linear filtering is outlined, followed by an introduction to the maximal overlap discrete wavelet transform (MODWT) in Section 4. The idea of one possible wavelet-based forecasting approach based on the Haar MODWT is presented in Section 5. Another, more general, wavelet-based forecasting approach grounded on the inverse MODWT theory (introduced in Section 6) is presented in Section 7. Section 8 summarises the results, discussing the potential use of other types of the wavelet transform, such as the discrete wavelet transform (DWT) and continuous wavelet transform (CWT), and draws conclusions.

The R statistical software (R Development Core Team, 2013) with a contributed package wmtsa (Constantine and Percival, 2012) was used.

\section{Boundary conditions in the literature}

In this section, we present a few wavelet-based models from the literature emphasising the way in which they handle boundary conditions.

Renaud et al. (2005) forecast input time series (financial futures and web site access data) by decomposing them into several components using the Haar MODWT of level $J$, obtaining the Haar MODWT wavelet and scaling coefficients. Consequently, the researchers model the dynamics of each level as a stationary autoregressive process with some parameters constrained to zero. As will be documented in detail below, the boundary conditions are handled correctly since the Haar filters have been used.

Soltani (2002) proposes using the wavelet transform combined with neural networks for (sunspot and Mackey-Glass) time series forecasting. Similarly to Renaud et al. (2005), Soltani (2002) uses the Haar MODWT coefficients since they can be obtained by filtering input time series with a causal linear filter and provide an additive decomposition of the input time series at the same time. The boundary conditions have thus been explicitly and correctly handled in the paper.

The idea of the decomposition of the input time series into several components employing the wavelet analysis and forecasting each component separately is pursued 
by Yousefi et al. (2005) in forecasting time series from the oil market. They decompose the input time series into the details and the smooth based on DWT and Daubechies filters with the first-level filter being of a length of 14. Consequently, each component is individually extrapolated using either a sine fit (for the detail components) or a spline fit (for the smooth component). Since the DWT details and smooth are affected by boundary conditions, the "quality" of the extrapolation is questionable. Moreover, we can find another unclear point in the paper, the authors mentioning (p. 270) an inverse transform application to extended details and smooth. This is confusing since no inverse transform is needed. If extended details and smooth are available, the forecast of the input time series should rather follow as a sum of these details and smooth.

Wong et al. (2003) introduce a wavelet-based algorithm for forecasting non-stationary time series (such as daily time series of exchange rates). They assume that an input time series can be expressed as the sum of three - trend, harmonic and irregular - components. The trend component is estimated by wavelets, namely being "equalled" to the high-scale dynamics of the input time series. An estimate of the harmonic component is obtained by so-called hidden periodicities analysis by wavelets. The irregular component is obtained by subtracting the estimated trend and the harmonic component from the input time series. It is modelled as a stationary ARMA process. The trend component is forecasted by extrapolation, namely, by fitting a cubic polynomial to the last portion of the component. Forecasts of the harmonic and irregular components can be added to the forecast of the trend component, resulting in an overall forecast of the input time series. Again, the effect of the boundary conditions in the extrapolation of the trend does not seem to be explicitly handled, thus being questionable.

Conejo et al. (2005) propose a wavelet-based algorithm for constructing up to one-day-ahead forecasts of hourly electricity price time series. Their idea consists in decomposing the input hourly time series into three detail series (levels 1,2,3) and one smooth time series of level 3 using Daubechies wavelets. The construction of these detail and smooth time series is based on the DWT. Consequently, an ARIMA model is fitted to each of the detail series (levels 1,2,3) and smooth series, constructing up to one-day-ahead forecasts of the hourly data. Consequently, the authors claim to have applied the inverse transform to the forecasted detail and smooth series, having obtained an overall forecast of the original input time series. We can see some unclear points in the procedure outlined above. Firstly, the right tails of the detail and smooth series are affected by the boundary conditions. Therefore, it is questionable whether the method that Conejo et al. (2005) use to forecast the detail and smooth series is the correct way to proceed. Moreover, the application of the inverse transform to the forecasted detail and smooth series does not seem to be meaningful since only the sum of the forecasts is necessary to achieve an overall forecast of the input time series.

Based on the literature review, it seems obvious that certain forecasting procedures have not been implemented correctly in some papers. That is why we provide an intuitive understanding of the MODWT below. Further, we address the issue of boundary conditions. In addition, the role of the inverse MODWT will be clearly explained. 


\section{Linear filtering}

While aiming at introducing the MODWT, we start with the theory of linear filtering at first. The introduction to linear filtering is short, the reader being referred to, e.g., Percival and Walden (2002) for further details.

\subsection{Linear filtering}

Let us assume a real-valued non-random sequence $\left\{a_{l}: l=B, \ldots, U\right\}$ called a linear filter, where $B$ and $U$ are integers such that $B \leq U$. The values of $a_{B}$ and $a_{U}$ are non-zero by definition. Often, it may be convenient to define the values of $a_{l}$ also for integers $l<B$ or $l>U-$ then these values are zero by definition. The length of $\left\{a_{l}\right\}$ is defined to be $U-B+1$. Even though we may refer to $a_{l}$ for any integer value of $l$, the notation $\left\{a_{l}: l=B, \ldots, U\right\}$ thus explicitly emphasises the length of the filter. This notation will often be abbreviated to $\left\{a_{l}\right\}$ if no confusion can arise as to what the values of $B$ and $U$ are. If $B \geq 0$, the filter $\left\{a_{l}: l=B, \ldots, U\right\}$ will be called a causal filter. Otherwise, it will be called a non-causal filter.

The sequence $\left\{a_{l}\right\}$ serves as the time-domain representation of the linear filter. The frequency-domain representation of the linear filter is defined as the Fourier transform of $\left\{a_{l}\right\}$,

$$
F_{a}(f) \equiv \sum_{l=-B}^{U} a_{l} \exp (-i 2 \pi f l), \quad \text { for } f \in R
$$

where $i$ is the imaginary unit and $f$ is a real-valued variable called frequency. $F_{a}(f)$ is called a frequency response function. The square of the modulus of the frequency response function, i.e., $\left|F_{a}(f)\right|^{2}$, is called a squared gain function. The squared gain function is a real-valued, even and periodic function of $f$, the period being equal to unity. Complete characterisation of $\left|F_{a}(f)\right|^{2}$ for $f \in \mathrm{R}$ is thus given by the values of $\left|F_{a}(f)\right|^{2}$ for $0 \leq f \leq 1 / 2$. Hereafter, the properties of squared gain functions of linear filters will be thus discussed only for the range of frequencies $0 \leq f \leq 1 / 2$.

Let us assume a real-valued discrete-time stochastic process $\left\{X_{t}: t=\ldots,-1,0,1, \ldots\right\}$. The result of linear filtering of $\left\{X_{t}\right\}$ with the linear filter $\left\{a_{l}\right\}$ is a stochastic process $\left\{Y_{t}: t=\ldots,-1,0,1, \ldots\right\}$ defined as

$$
Y_{t} \equiv \sum_{l=-B}^{U} a_{l} X_{t-l}, \quad \text { for } t=\ldots,-1,0,1, \ldots
$$

If $\left\{X_{t}\right\}$ is stationary with a square summable autocovariance function $\left\{\gamma_{X, \tau}: \tau=\ldots,-1\right.$, $0,1, \ldots\}$, the spectrum of $\left\{X_{t}\right\}$ is defined as the Fourier transform of $\left\{\gamma_{X, \tau}\right\}$, i.e.

$$
S_{X}(f) \equiv \sum_{\tau=-\infty}^{\infty} \gamma_{X, \tau} \exp (-i 2 \pi f \tau), \quad \text { for } f \in R
$$


The spectrum is an even and periodic function of frequency, the period being equal to unity. Therefore, the properties of spectra will be discussed only for the range of frequencies $0 \leq f \leq 1 / 2$. Since $\left\{Y_{t}\right\}$ is the output from linear filtering of a stationary $\left\{X_{t}\right\}$ with $\left\{a_{l}\right\}$, it is also stationary with its spectrum given as

$$
S_{Y}(f) \equiv\left|F_{a}(f)\right|^{2} S_{X}(f), \quad \text { for } 0 \leq f \leq 1 / 2
$$

The transition from $S_{X}(f)$ to $S_{Y}(f)$ is thus mediated by $\left|F_{a}(f)\right|^{2}$.

An ideal linear filter with the nominal pass-band $[d, u]$ (for $0 \leq d \leq 1 / 2,0 \leq u \leq 1 / 2$ and $d \leq u$ ) is defined as a linear filter the squared gain function of which is given as

$$
\left|F_{\text {ideal }}(f)\right|^{2} \equiv\left\{\begin{array}{lc}
1, & \text { for } d \leq f \leq u, \\
0, & \text { otherwise. }
\end{array}\right.
$$

Such an ideal linear filter would pass the frequency content of $\left\{X_{t}\right\}$ in the frequency interval $d \leq f \leq u$ and eliminate any other frequency content. For further details on linear filters and linear filtering of stochastic processes, see, e.g., Percival and Walden (2002).

\section{Maximal overlap discrete wavelet transform}

In this section, we define the concept of the maximal overlap discrete wavelet transform (MODWT). Our introduction is based mainly on Percival and Walden (2002).

An emphasis is put on the boundary effects and the meaning of the MODWT and the inverse MODWT.

\subsection{MODWT wavelet and scaling filters}

MODWT wavelet and scaling filters are a special set of linear filters. First, let us start with the definition of the first-level MODWT wavelet filter and the first-level MODWT scaling filter, denoted as $\left\{h_{1, l}: l=0, \ldots, L_{1}-1\right\}$ and $\left\{g_{1, l}: l=0, \ldots, L_{1}-1\right\}$, where $L_{1}$ are the lengths of these filters, $L_{1}$ being always even. The filter $\left\{h_{1, l}\right\}$ has to fulfil the following properties:

$$
\begin{aligned}
& \sum_{l=0}^{L_{1}-1} h_{1, l}=0, \\
& \sum_{l=0}^{L_{1}-1} h_{1, l}^{2}=\frac{1}{2},
\end{aligned}
$$




$$
\sum_{l=0}^{L_{1}-1} h_{1, l} h_{1, l+2 n}=0, \quad \text { for } n \neq 0,
$$

and has to be an approximately ideal filter for the nominal pass-band $[1 / 4,1 / 2]$. The filter $\left\{g_{1, l}\right\}$ is defined as

$$
g_{1, l} \equiv(-1)^{l+1} h_{1, L_{1}-1-l}, \quad \text { for } l \in Z
$$

The properties of $\left\{g_{1, l}\right\}$ follow from those of $\left\{h_{1, l}\right\}$, one of them being the fact that $\left\{g_{1, l}\right\}$ is an approximately ideal filter for the nominal pass-band $[0,1 / 4]$.

There are several sets of filters $\left\{h_{1, l}\right\}$ and $\left\{g_{1, l}\right\}$ available - Haar filters (i.e., the Haar set of wavelet and scaling filter), Daubechies filters, coiflet filters etc. The Haar and $\mathrm{D}(4)$ (i.e., the Daubechies extremal phase of length 4) $\left\{h_{1, l}\right\}$ and $\left\{g_{1, l}\right\}$ filters are plotted in Figure 1 for illustration. For the Haar filters $L_{1}=2$, whereas for the $\mathrm{D}(4)$ filters $L_{1}=4$. The reader can easily check that Equations 6, 7,8 and 9 are true.

\section{Figure 1}

From left to right: Haar $\left\{h_{1, l}\right\}$ and $\left\{g_{1, l}\right\}$ filters and $D(4)\left\{h_{1, l}\right\}$ and $\left\{g_{1, l}\right\}$ filters
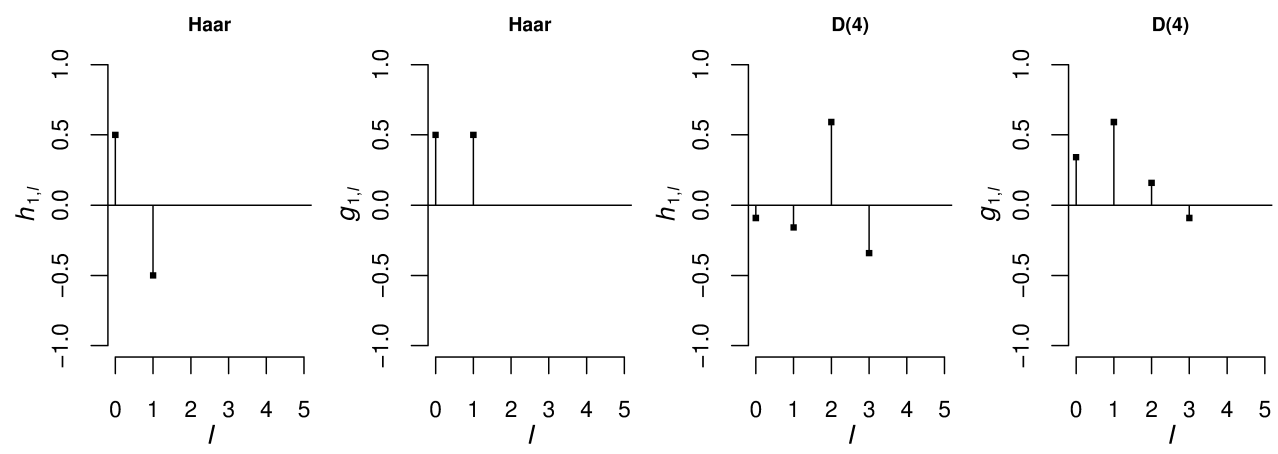

Using the first-level MODWT wavelet and scaling filters, it is possible to define the $j$ th (for $j=2,3, \ldots$ ) level MODWT wavelet filter, $\left\{h_{j, l} l l=0, \ldots, L_{j}-1\right\}$, and the $j$ th (for $j=2,3, \ldots$. ) level MODWT scaling filter, $\left\{g_{j, l}: l=0, \ldots, L_{j}-1\right\}$, both of the length

$$
L_{j}=\left(2^{j}-1\right)\left(L_{1}-1\right)+1 \text {, }
$$

For a detailed explanation of how these filters are constructed, see Percival and Walden (2002). It is important to stress that $\left\{h_{j, l}: l=0, \ldots, L_{j}-1\right\}$ is an approximately 
ideal filter with the nominal pass-band $\left[1 / 2^{j+1}, 1 / 2^{j}\right]$ and $\left\{g_{j, l}\right\}$ is an approximately ideal filter with the nominal pass band $\left[0,1 / 2^{j+1}\right]$.

The $j$ th-level Haar MODWT wavelet and scaling filters have a very simple form. More specifically, we can write (for $j=1,2, \ldots$ ):

$$
\begin{gathered}
h_{j, l} \equiv\left\{\begin{array}{cc}
1 / 2^{j}, & \text { for } l=0, \ldots, 2^{j-1}-1, \\
-1 / 2^{j}, & \text { for } l=2^{j-1}, \ldots, 2^{j}-1, \\
0, & \text { otherwise }
\end{array}\right. \\
g_{j, l} \equiv\left\{\begin{array}{cc}
1 / 2^{j}, & \text { for } l=0, \ldots, 2^{j}-1, \\
0, & \text { otherwise }
\end{array}\right.
\end{gathered}
$$

An illustration is provided in Figure 2. The first (second) row shows the Haar (D(4)) MODWT wavelet filters $\left\{h_{1, l}: l=0, \ldots, L_{1}-1\right\},\left\{h_{2, l}: l=0, \ldots, L_{2}-1\right\},\left\{h_{3, l}: l=0\right.$, ..., $\left.L_{3}-1\right\}$ together with the Haar $(\mathrm{D}(4))$ MODWT scaling filter $\left\{g_{3, l}: l=0, \ldots, L_{3}-1\right\}$.

\section{Figure 2}

MODWT filters $\left\{h_{1, l}\right\},\left\{h_{2, l}\right\},\left\{h_{3, l}\right\}$ and $\left\{g_{3, l}\right\}$, Haar (1 ${ }^{\text {st }}$ row $), D(4)\left(2^{\text {nd }}\right.$ row)
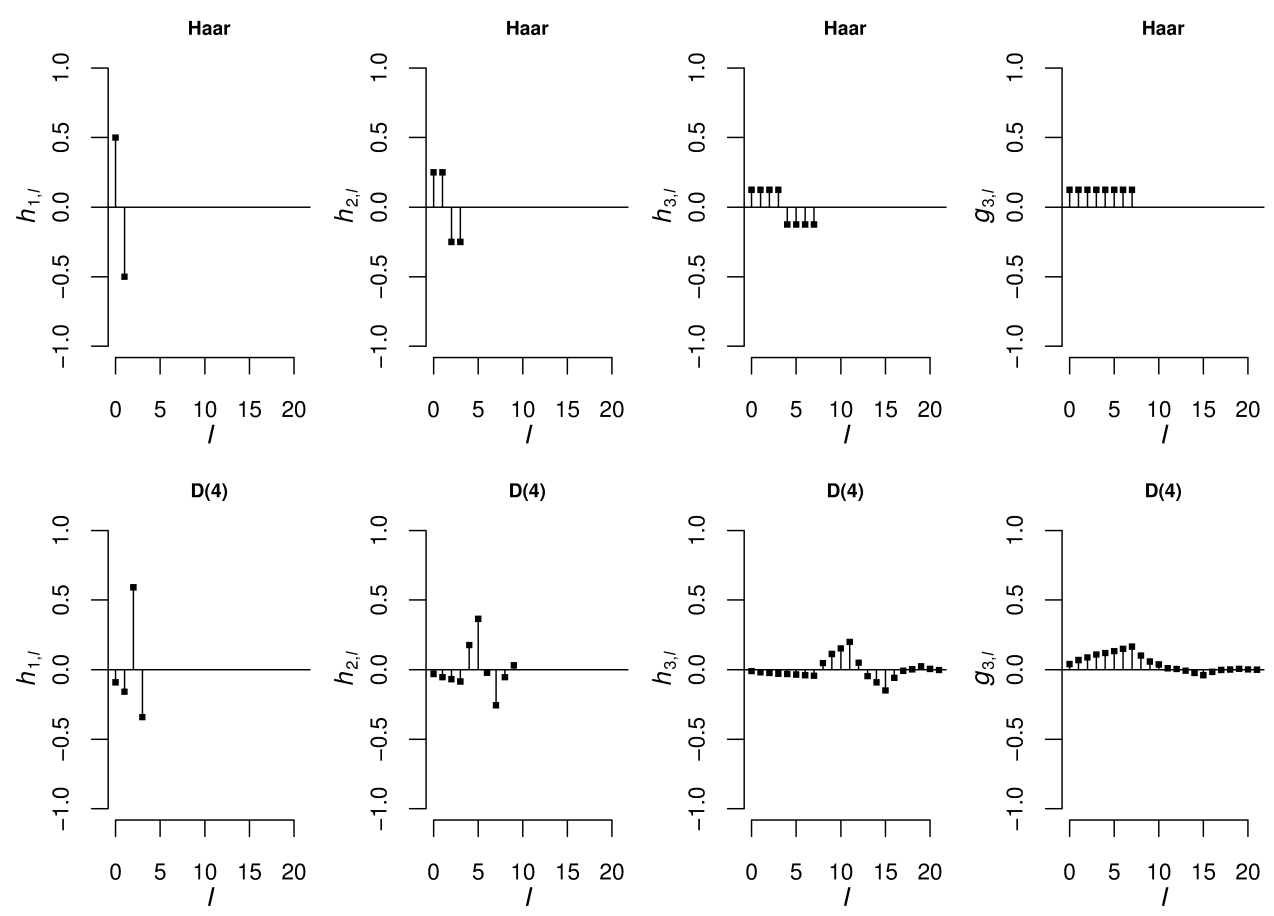


\subsection{MODWT coefficients}

The $j$ th-level (for $j=1,2, \ldots$.$) MODWT wavelet coefficients \left\{W_{j, t}: t=\ldots,-1,0,1, \ldots\right\}$ and the $j$ th-level (for $j=1,2, \ldots .$.$) MODWT scaling coefficients \left\{V_{j, t}: t=\ldots,-1,0,1, \ldots\right\}$ of a stochastic process $\left\{X_{t}: t=\ldots,-1,0,1, \ldots\right\}$ are defined as

$$
\begin{gathered}
W_{j, t} \equiv \sum_{l=0}^{L_{j}-1} h_{j, l} X_{t-l}, \quad \text { for } t=\ldots,-1,0,1, \ldots ., \\
V_{j, t} \equiv \sum_{l=0}^{L_{j}-1} g_{j, l} X_{t-l}, \quad \text { for } t=\ldots,-1,0,1, \ldots . .
\end{gathered}
$$

Further, we can write (for $t=\ldots,-1,0,1, \ldots$ )

$$
\begin{aligned}
\sum_{j=1}^{J} W_{j, t}+V_{J, t} \equiv & \sum_{j=1}^{J} \sum_{l=0}^{L_{j}-1} h_{j, l} X_{t-l}+\sum_{l=0}^{L_{J}-1} g_{J, l} X_{t-l}= \\
& \sum_{l=0}^{L_{J}-1}\left(\sum_{j=1}^{J} h_{j, l}+g_{J, l}\right) X_{t-l},
\end{aligned}
$$

where $J$ is a given (arbitrary) positive integer and where we use the notation introduced above, namely the fact that by definition $h_{j, l}=0$ for $l>L_{j}-1$ (and for $l<0$ ). Appealing to Equations 11 and 12, for the Haar MODWT filters, we get

$$
\sum_{j=1}^{J} h_{j, l}+g_{J, l}= \begin{cases}1, & \text { for } l=0, \\ 0, & \text { for } l \neq 0,\end{cases}
$$

which is, however, not true in general (i.e., for MODWT filters other than the Haar ones). Consequently, it follows from Equation 15 that for the Haar MODWT filters we have

$$
\sum_{j=1}^{J} W_{j, t}+V_{J, t}=X_{t}, \quad \text { for } t=\ldots,-1,0,1, \ldots
$$

Equation 17 is important since it tells us that using the Haar MODWT filters, we can additively decompose the input time series into the MODWT wavelet and scaling coefficients. Each series in this decomposition is associated with a different frequency content of the input time series since the MODWT filters can be considered approximately ideal filters for non-overlapping frequency bands (see above). Another crucial point to note (elaborated below in more detail) is that the MODWT wavelet and scaling coefficients are obtained by linear filtering $\left\{X_{t}\right\}$ with filters $\left\{h_{j, l}\right\}$ and $\left\{g_{j, l}\right\}$, which are causal. 
Since Equation 16 is true for the Haar MODWT filters and an arbitrary $J$, it must be also true for $J=3$. And indeed, the sum of the Haar MODWT filters presented in the first row of Figure 2 is shown in the top plot of Figure 3, being in agreement with the identity of Equation 16. On the other hand, Equation 16 is not true for general MODWT filters which can be verified by summing up the D(4) MODWT filters in the bottom row of Figure 2. The sum is presented in the bottom plot of Figure 3 and is obviously not (even approximately) equal to the right-hand side of Equation 16.

\section{Figure 3}

$h_{1, l}+h_{2, l}+h_{3, l}+g_{3, l}, l=0, \ldots, L_{3}-1$, for Haar MODWT filters (top plot) and for D(4) MODWT filters (bottom plot)
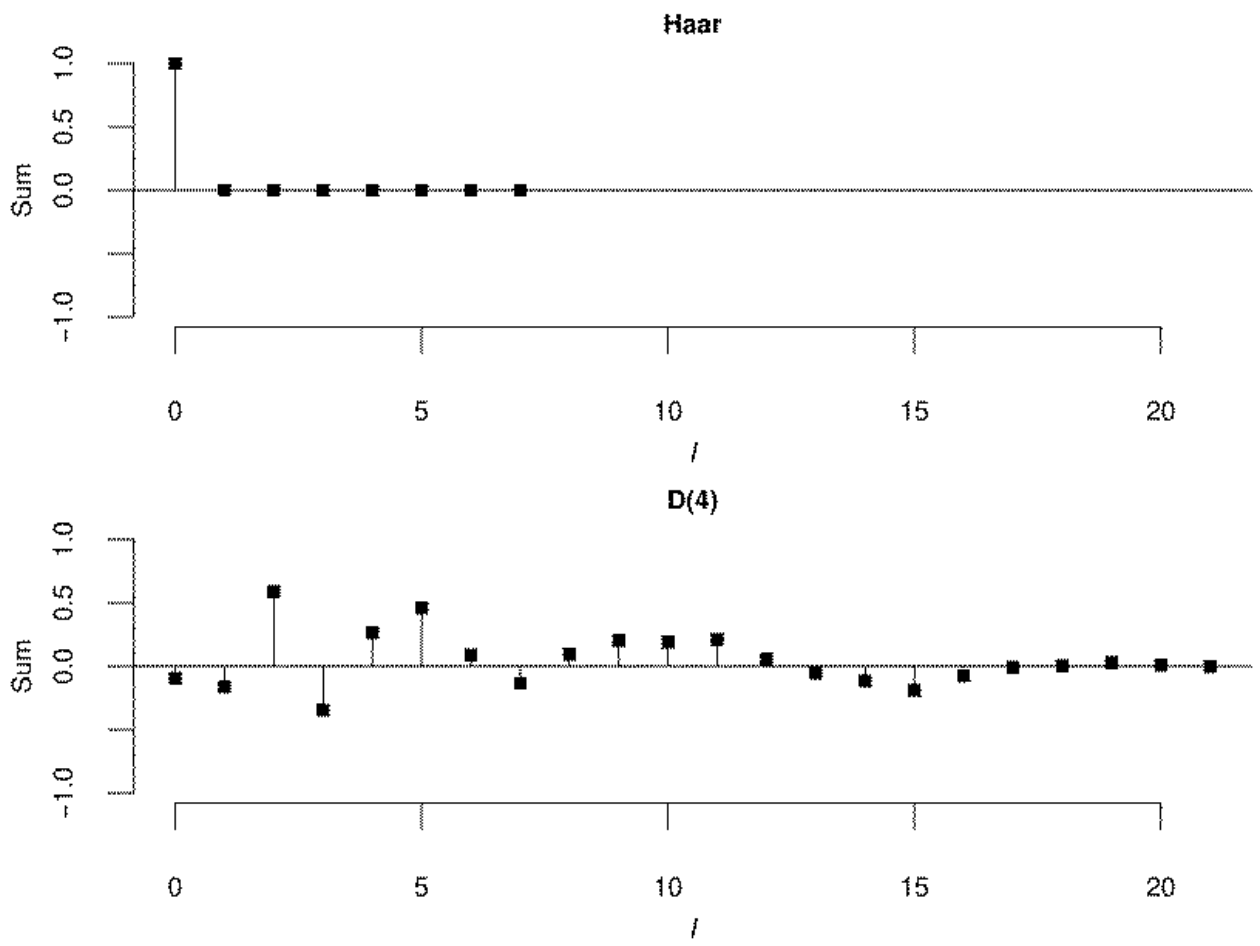

\section{Wavelet-based forecasting approach using MODWT coefficients}

Thanks to their properties, the Haar MODWT coefficients can be used as an element of the wavelet-based forecasting approach outlined in Section 1. In real-life applications, so-called boundary conditions are to be taken into consideration.

\subsection{Surrogates for MODWT wavelet and scaling coefficients}

Let us assume that we have observed a finite portion $\left\{X_{t}: t=0, \ldots, N-1\right\}$ of length $N$ of the process $\left\{X_{t}: t=\ldots-1,0,1, \ldots\right\}$. Using this finite portion only, we would like to obtain finite portions $\left\{W_{j, t}: t=0, \ldots, N-1\right\}$ and $\left\{V_{j, t}: t=0, \ldots, N-1\right\}$ of the processes of 
the $j$ th-level MODWT wavelet coefficients, $\left\{W_{j, t}: t=\ldots-1,0,1, \ldots\right\}$, and the $j$ th-level MODWT scaling coefficients $\left\{V_{j, t}: t=\ldots-1,0,1, \ldots\right\}$ (for $\left.j=1, \ldots, J\right)$. For ease of notation, we assume that $N \geq L_{J}-1$. Since $\left\{W_{j, t}: t=\ldots-1,0,1, \ldots\right\}$ and $\left\{V_{j, t}: t=\ldots-1,0,1, \ldots\right\}$ are obtained by linear filtering of $\left\{X_{t}: t=\ldots,-1,0,1, \ldots\right\}$ with filters $\left\{h_{j, l}: l=0,1, \ldots\right.$, $\left.L_{j}-1\right\}$ and $\left\{g_{j, l}: l=0, \ldots, L_{j}-1\right\}$ (see Equations 13 and 14), it follows that we cannot obtain the values of $W_{j, t}$ and $V_{j, t}$ for $t=0, \ldots, L_{j}-2$ from $\left\{X_{t}: t=0, \ldots, N-1\right\}$, because these values are determined by at least one such $X_{t}$ for which $t<0$; however, such $X_{t} \mathrm{~s}$ are not available in $\left\{X_{t}: t=0, \ldots, N-1\right\}$.

Some boundary conditions can be introduced, which would provide surrogates for the missing $X_{t}$ (for $t<0$ ) so that $W_{j, t}$ and $V_{j, t}$, for $t=0, \ldots, L_{j}-2$, could be calculated. Examples of some commonly used boundary conditions are circularity and reflection conditions. These define the surrogates for $X_{t}$ not only for $t<0$ but also for $t>N-1$. The situations where we need surrogates for $X_{t}$ also for $t>N-1$ will be clarified in Section 7. The definition of surrogates imposed by the circularity boundary conditions is as follows:

$$
X_{t} \equiv X_{t \bmod N}, \quad \text { for } t<0 \text { or } t>N-1
$$

where mod denotes the operation modulo. The time series is thus treated as being periodic with the period equal to $N$. On the other hand, the reflection boundary conditions reflect the time series $\left\{X_{t}: t=0, \ldots, N-1\right\}$ about its right tail at first. The surrogates for $X_{t}$, for $t=N, \ldots, 2 N-1$, are defined by this reflection. More specifically, we can write

$$
X_{t} \equiv X_{2 N-1-t}, \quad \text { for } t=N, \ldots, 2 N-1 .
$$

The reflection results in an extended time series of length $2 N$. Consequently, circularity boundary conditions are imposed onto this extended (reflected) time series. This leads to the definition of further surrogates for $X_{t}$, namely those for $t<0$ and $t>2 N-1$.

Let us denote the sequences of the $j$ th-level MODWT wavelet and the $j$ th-level MODWT scaling coefficients calculated from $\left\{X_{t}: t=0, \ldots, N-1\right\}$, using some boundary conditions, as $\left\{W_{j, t}{ }^{(b)}: t=0, \ldots, N-1\right\}$ and $\left\{V_{j, t}^{(b)}: t=0, \ldots, N-1\right\}$. The superscript $(b)$ emphasises the fact that some $W_{j, t}{ }^{(b)}$ and $V_{j, t}{ }^{(b)}$, namely those with $t=0, \ldots, L_{j}-2$, make use of the boundary conditions, denoted as $(b)$, in their calculation. The coefficients $W_{j, t}^{(b)}$ and $V_{j, t}{ }^{(b)}$, for $t=0, \ldots, L_{j}-2$, are called coefficients affected by boundary conditions and, generally, $W_{j, t}^{(b)} \neq W_{j, t}$ and $V_{j, t}^{(b)} \neq V_{j, t}$ for $t=0, \ldots, L_{j}-2$, where $W_{j, t}$ and $V_{j, t}$ denote the wavelet and scaling coefficients as defined by Equations 13 and 14, where $\left\{X_{t}: t=\ldots,-1,0,1, \ldots\right\}$ consists of the true values only and no surrogates.

Software packages generally output the sequences $\left\{W_{j, t}{ }^{(b)}: t=0, \ldots, N-1\right\}$ and $\left\{V_{j, t}^{(b)}: t=0, \ldots, N-1\right\}$ when analysing the realisation of $\left\{X_{t}: t=0, \ldots, N-1\right\}$. This may lead to a false impression that all the values in these sequences can be used for further analysis. However, since the surrogates for $X_{t}$, for $t<0$, imposed by 
the boundary conditions do not coincide with the true (unobserved) values, $W_{j, t}{ }^{(b)}$ and $V_{j, t}{ }^{(b)}$ for $t=0, \ldots, L_{j}-2$ generally deviate from the true (unavailable) $W_{j, t}$ and $V_{j, t}$ for $t=0, \ldots, L_{j}-2$, the deviation usually being the greater the closer $t$ is to zero. This implies that coefficients affected by the boundary conditions, i.e., $W_{j, t}^{(b)}$ and $V_{j, t}{ }^{(b)}$ for $t=0, \ldots, L_{j}-2$, should be handled with caution and preferably excluded from further analysis if no clear justification for their use is given.

An illustration is presented in Figure 4. A finite realisation $\left\{X_{t}: t=0, \ldots, 9\right\}$ of length $N=10$ of a stochastic process is given in the top plot. The observed values of $\left\{X_{t}: t=0, \ldots, 9\right\}$ are marked with empty circles. The regions shaded with grey vertical lines (i.e., those with $t<0$ and $t>9$ ) represent the regions in which the values of $X_{t}$ are not known to the researcher. Hypothetically, if these values were known, they would be given by the empty circles in the shaded regions of the top plot. Furthermore, two other boundary conditions are depicted in the top plot. The values of $X_{t}$ for $t<0$ and $t>9$ imposed by circularity boundary conditions are marked with filled circles, those imposed by reflection boundary conditions being marked with crosses. The horizontal line denotes the position of zero on the vertical axis. Furthermore, the first-level, $\left\{W_{1, t}^{(b)}: t=0, \ldots, 9\right\}$, second-level, $\left\{W_{2, t}^{(b)}: t=0, \ldots, 9\right\}$, and third-level, $\left\{W_{3, t}{ }^{(b)}: t=0, \ldots, 9\right\}$, Haar MODWT wavelet coefficients together with the third-level Haar scaling coefficients, $\left\{V_{3, t}^{(b)}: t=0, \ldots, 9\right\}$, are plotted in the second, third, fourth and fifth plots from the top. The coefficients affected by the boundary conditions are to the left of the dotted vertical lines. There are three sets of these coefficients:

- The first set, depicted by empty circles (to the left of the vertical dotted lines), corresponds to the hypothetical situation where the true values of $X_{t}$ from the shaded region of the top plot are used for the calculation of the coefficients.

- The second set is depicted by filled circles and corresponds to the calculation of MODWT coefficients using the circularity boundary conditions of the top plot.

- The third set is depicted by crosses and corresponds to the calculation of MODWT coefficients using the reflection boundary conditions of the top plot.

The coefficients not affected by the boundary conditions are to the right of the dotted vertical lines and are unique (for each level). They are also depicted by empty circles since they do not employ any boundary conditions and use only the true values of the input time series in their calculation. Now, whatever boundary conditions (of the three) we choose, we can visually check that we always get

$$
\sum_{j=1}^{3} W_{j, t}^{(b)}+V_{3, t}^{(b)}=X_{t}, \quad t=0, \ldots, 9 .
$$

It is obvious, however, that the dynamics of the coefficients affected by either circularity or reflection boundary conditions (see the filled circles or crosses) is different from the dynamics that would be observed if the true values of the input time series in the shaded regions of the upper plot were known. 


\section{Figure 4}

Illustration of the impact of the circularity boundary conditions (filled circles) and reflection boundary conditions (crosses) on the time series of the Haar MODWT wavelet and Haar MODWT scaling coefficients. See the text for a description.
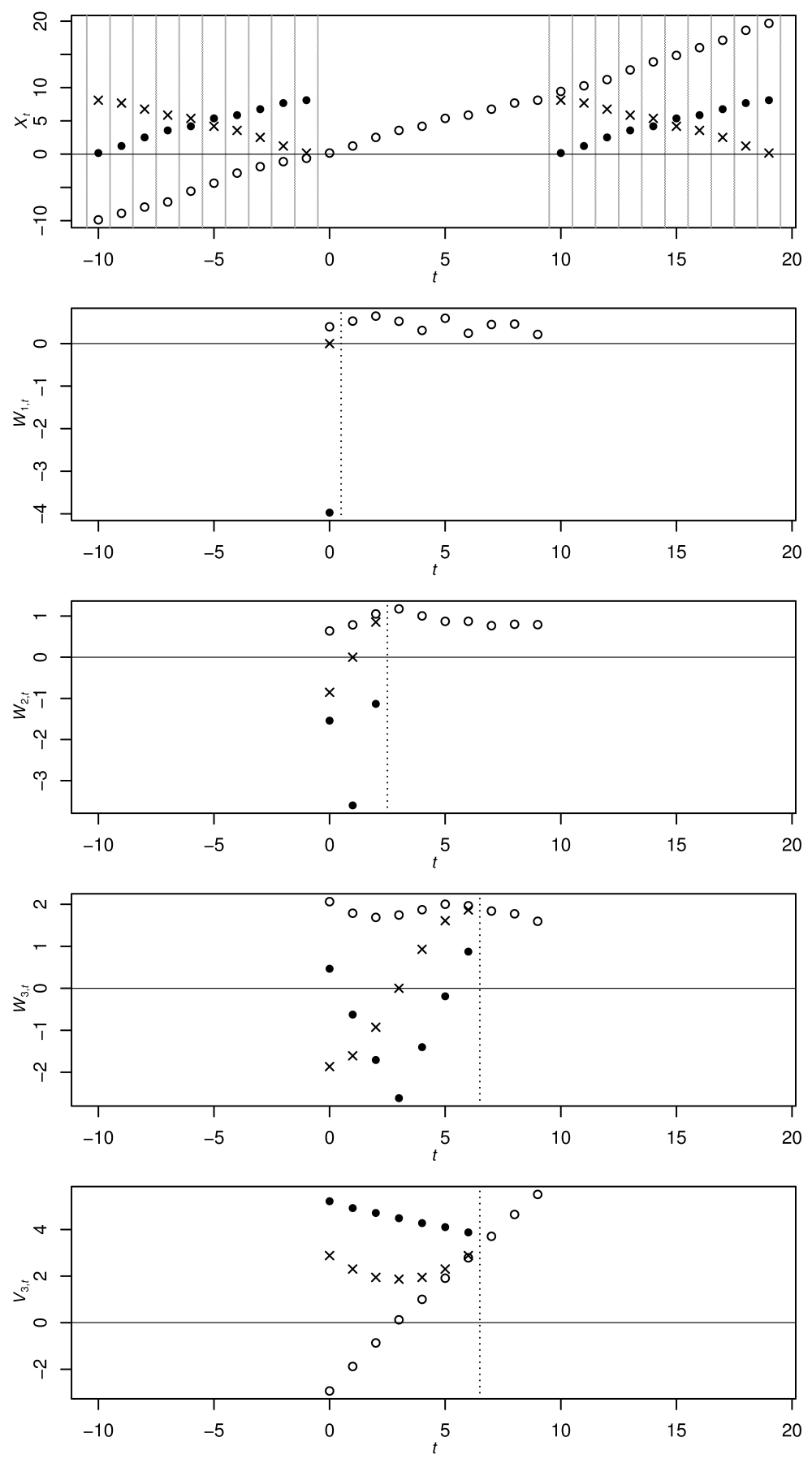


\subsection{Forecasting}

It follows from the previous paragraphs that the wavelet-based forecasting approach outlined in Section 1 could potentially be implemented using the additive decomposition of the input time series into the Haar MODWT wavelet coefficients (see also Renaud et al., 2005, and Soltani, 2002). While modelling and estimating the parameters of the models for each of the individual coefficient series, the coefficients affected by the boundary conditions (such as the circularity or reflection ones) should be excluded if no clear justification for their use is given. The reason for the exclusion follows from the fact that these coefficients are generated by a mechanism using "ad hoc" boundary conditions, which is different from the mechanism that generates coefficients not affected by the boundary conditions. Therefore, the coefficients affected by the boundary conditions do not follow the same model which applies to the coefficients not affected by the boundary conditions. Fortunately, if $N \gg L_{j}$, many coefficients not affected by the boundary conditions are still left at the right tail of $\left\{W_{j, t}{ }^{(b)}: t=0, \ldots, N-1\right\}$ and $\left\{V_{j, t}{ }^{(b)}: t=0, \ldots, N-1\right\}$, which is desirable for the forecasting objectives.

\section{Inverse MODWT}

The reconstruction of the input time series from MODWT coefficients given by Equation 17 is true only for Haar filters. For general filters, the reconstruction of the input time series from the MODWT coefficients must be done through the inverse MODWT, namely through the MODWT details and smooth.

\subsection{MODWT details and smooth}

Let the linear filters $\left\{h_{R, j, l}: l=-\left(L_{j}-1\right), \ldots, 0\right\}$ and $\left\{g_{R, j, l}: l=-\left(L_{j^{-}} 1\right), \ldots, 0\right\}$ of length $L_{j}$ (for $j=1,2, \ldots$ ) be defined as follows:

$$
\begin{aligned}
& h_{R, j, l} \equiv h_{j,-l}, \quad \text { for } l=-\left(L_{j}-1\right), \ldots, 0, \\
& g_{R, j, l} \equiv g_{j,-l}, \quad \text { for } l=-\left(L_{j}-1\right), \ldots, 0 .
\end{aligned}
$$

Consequently, the $j$ th-level (for $j=1,2, \ldots$ ) MODWT detail $\left\{D_{j, t}: t=\ldots,-1,0,1, \ldots\right\}$ and the $j$ th-level (for $j=1,2, \ldots$ ) MODWT smooth $\left\{S_{j, t}: t=\ldots,-1,0,1, \ldots\right\}$ are obtained from MODWT wavelet and scaling coefficients, $\left\{V_{j, t}: t=\ldots,-1,0,1, \ldots\right\}$ and $\left\{W_{j, t}: t=\ldots,-1,0,1, \ldots\right\}$, as follows:

$$
\begin{aligned}
& D_{j, t} \equiv \sum_{l=-\left(L_{j}-1\right)}^{0} h_{R, j, l} W_{j, t-l}=\sum_{l=0}^{L_{j}-1} h_{j, l} W_{j, t+l}, \quad \text { for } t=\ldots,-1,0,1 \ldots, \\
& S_{j, t} \equiv \sum_{l=-\left(L_{j}-1\right)}^{0} g_{R, j, l} V_{j, t-l}=\sum_{l=0}^{L_{j}-1} g_{j, l} V_{j, t+l}, \quad \text { for } t=\ldots,-1,0,1 \ldots
\end{aligned}
$$

Since the coefficients $\left\{W_{j, t}: t=\ldots,-1,0,1, \ldots\right\}$ and $\left\{V_{j, t}: t=\ldots,-1,0,1, \ldots\right\}$ themselves are outputs from linear filtering of $\left\{X_{t}: t=\ldots,-1,0,1, \ldots\right\}$ with linear filters $\left\{h_{j, l}\right\}$ and $\left\{g_{j, l}\right\}$ (see Equations 13 and 14), the details and smooths of Equations 23 and 24 
can be rewritten directly as outputs from linear filtering of $\left\{X_{t}\right\}$ with (some newly defined) linear filters. More specifically, we can write (see Percival and Walden, 2002, Section 5.11):

$$
\begin{aligned}
& D_{j, t}=\sum_{l=-\left(L_{j}-1\right)}^{L_{j}-1} d_{j, l} X_{t-l}, \quad \text { for } t=\ldots,-1,0,1, \ldots \\
& S_{j, t}=\sum_{l=-\left(L_{j}-1\right)}^{L_{j}-1} s_{j, l} X_{t-l}, \quad \text { for } t=\ldots,-1,0,1, \ldots
\end{aligned}
$$

where linear filters $\left\{d_{j, l}: l=-\left(L_{j}-1\right), \ldots,-1,0,1, \ldots,\left(L_{j}-1\right)\right\}$ and $\left\{s_{j, l}: l=-\left(L_{j}-1\right), \ldots,-1\right.$, $\left.0,1, \ldots,\left(L_{j}-1\right)\right\}$, both of length $2 L_{j}-1$, are defined as

$$
\begin{aligned}
& d_{j, l} \equiv \sum_{u=0}^{L_{j}-1} h_{j, u} h_{j, u+l}, \quad \text { for } l=-\left(L_{j}-1\right), \ldots,-1,0,1, \ldots, L_{j}-1, \\
& s_{j, l} \equiv \sum_{u=0}^{L_{j}-1} g_{j, u} g_{j, u+l}, \quad \text { for } l=-\left(L_{j}-1\right), \ldots,-1,0,1, \ldots, L_{j}-1 .
\end{aligned}
$$

Percival and Walden (2002, Chapter 5.4) show that $\left\{d_{j, l}\right\}$ and $\left\{s_{j, l}\right\}$ are approximately ideal filters for the nominal pass bands $\left[1 / 2^{j+1}, 1 / 2^{j}\right]$ and $\left[0,1 / 2^{j+1}\right]$, respectively. The Haar $\left\{d_{1, l}\right\},\left\{d_{2, l}\right\},\left\{d_{3, l}\right\}$ and $\left\{s_{3, l}\right\}$ filters are presented in the top plot of Figure 5, the bottom plot showing the $\mathrm{D}(4)\left\{d_{1, l}\right\},\left\{d_{2, l}\right\},\left\{d_{3, l}\right\}$ and $\left\{s_{3, l}\right\}$ filters. All these filters are symmetric around zero and are non-causal.

Let $J$ be an arbitrary positive integer. The following identity is generally true:

$$
\sum_{j=1}^{J} d_{j, l}+s_{J, l}= \begin{cases}1, & \text { for } l=0, \\ 0, & \text { for } l \neq 0 .\end{cases}
$$

For the Haar and $\mathrm{D}(4)$ filters and $J=3$, a visual check of the identity is provided in Figure 6. Further, we can write (for $t=\ldots,-1,0,1, \ldots$ ):

$$
\begin{gathered}
\sum_{j=1}^{J} D_{j, t}+S_{J, t} \equiv \sum_{j=1}^{J} \sum_{l=-\left(L_{j}-1\right)}^{L_{j}-1} d_{j, l} X_{t-l}+\sum_{l=-\left(L_{J}-1\right)}^{L_{J}-1} s_{J, l} X_{t-l}= \\
\sum_{l=-\left(L_{J}-1\right)}^{L_{J}-1}\left(\sum_{j=1}^{J} d_{j, l}+s_{J, l}\right) X_{t-l} .
\end{gathered}
$$

Consequently, appealing to the identity of Equation 29, we can write:

$$
X_{t}=\sum_{j=1}^{J} D_{j, t}+S_{J, t} .
$$

We can conclude that the time series of details and smooths can be generally used to additively decompose the input time series $\left\{X_{t}\right\}$ into several contributions. The contributions are associated with different and approximately non-overlapping ranges of frequencies. 


\section{Figure 5}

$\left\{d_{1, l}\right\},\left\{d_{2, l}\right\},\left\{d_{3, l}\right\}$ and $\left\{s_{3, l}\right\}$ for Haar (top plot) and D(4) filters (bottom plot)
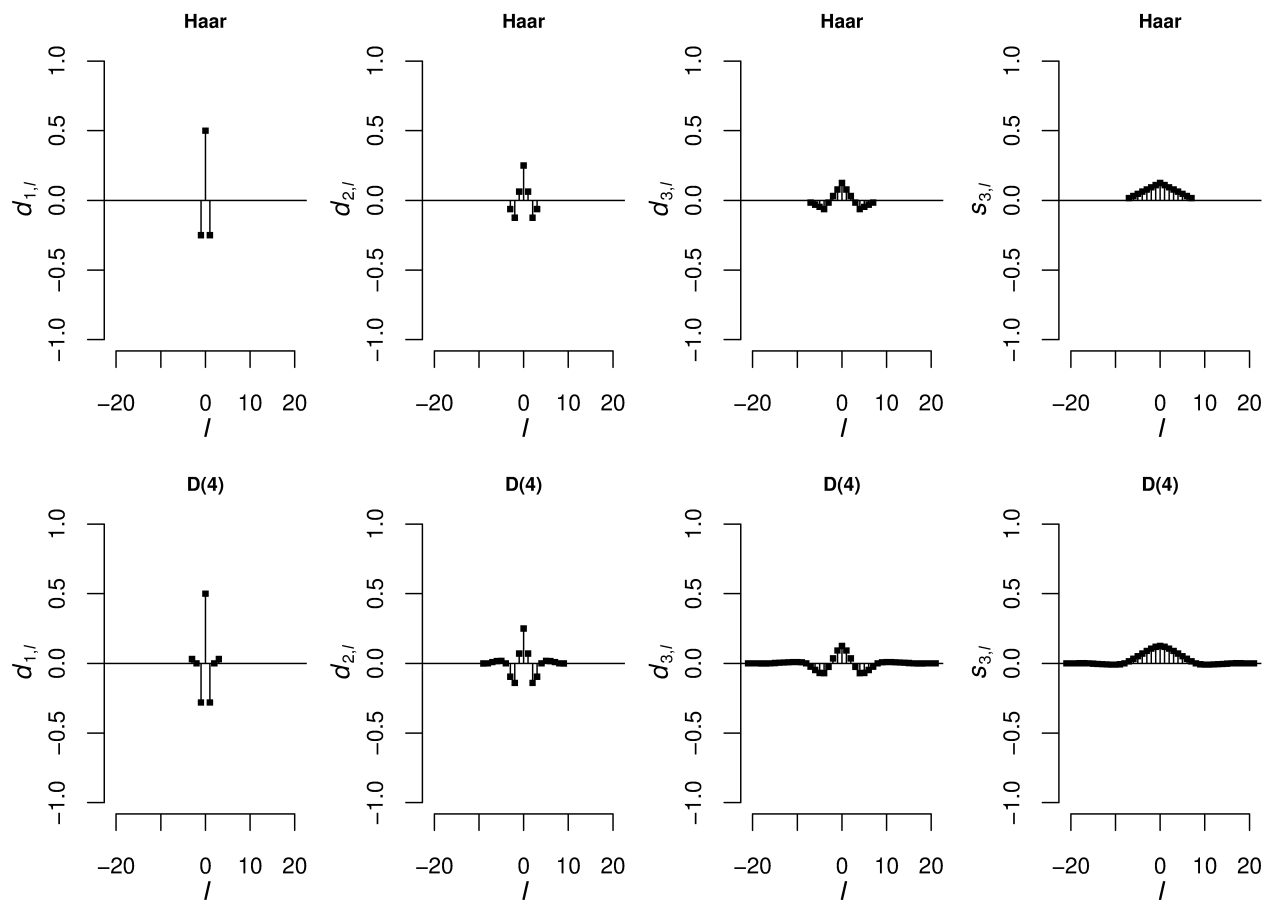

\section{Figure 6}

$d_{1, I}+d_{2, I}+d_{3, I}+s_{3, l}, I=-\left(L_{3}-1\right), \ldots, L_{3}-1$, for Haar MODWT filters (top plot) and D(4) MODWT filters (bottom plot)
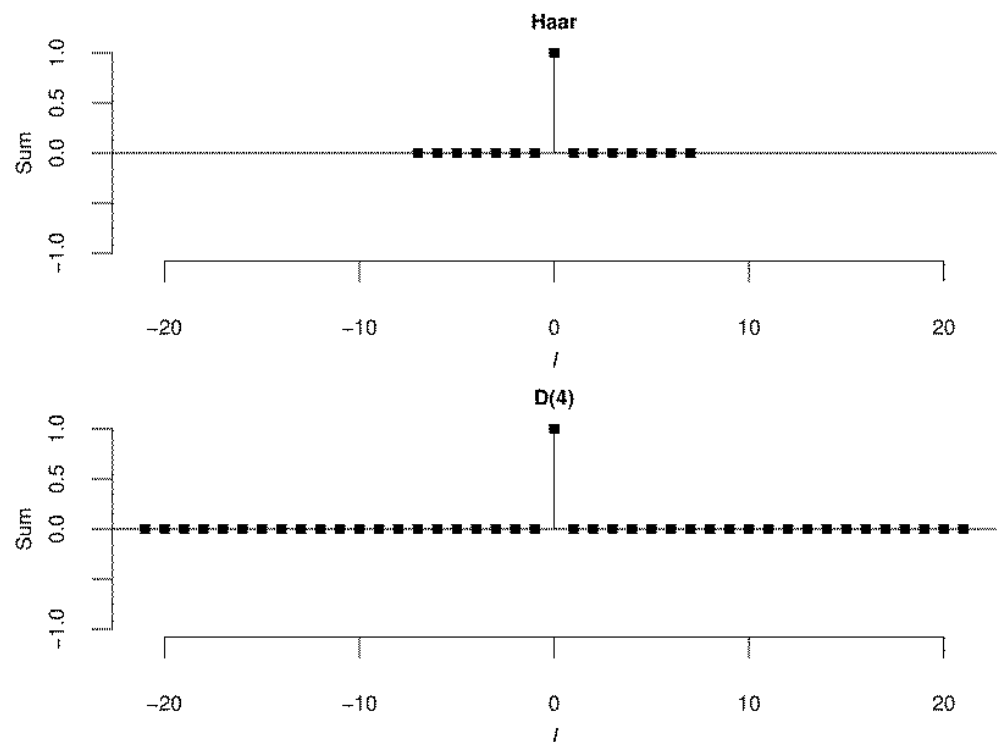


\section{Wavelet-based forecasting approach using inverse MODWT}

The MODWT details and smooths are obtained by filtering the input time series with non-causal linear filters. This fact has important consequences if the input time series is decomposed into details and smooths as a part of the wavelet-based forecasting approach of Section 1. These consequences will be discussed below.

\subsection{Surrogates for the MODWT details and smooths}

Let us deal with the task of how to obtain $\left\{D_{j, t}: t=0, \ldots, N-1\right\}$ and $\left\{S_{j, t}: t=0, \ldots, N-1\right\}$ (for $j=1, \ldots, J$ ), i.e., finite portions of length $N$ of $\left\{D_{j, t}: t=\ldots,-1,0,1, \ldots\right\}$ and $\left\{S_{j, t}: t=\ldots,-1,0,1, \ldots\right\}$, from $\left\{X_{t}: t=0, \ldots, N-1\right\}$. For ease of notation, let us assume that $N \geq L_{J}-1$. To obtain $D_{j, t}$ and $S_{j, t}$ for a specific value of $t$ the values of $X_{t-l}$ for $l=-\left(L_{j}-1\right), \ldots,-1,0,1, \ldots, L_{j}-1$ are needed (see Equations 25 and 26). Therefore, the values of $D_{j, t}$ and $S_{j, t}$ for $t=0, \ldots, L_{j}-2$ cannot be calculated directly from $\left\{X_{t}: t=0, \ldots, N-1\right\}$ since the calculation requires the knowledge of the values of $X_{t}$ for at least one $t<0$. Similarly, the values of $D_{j, t}$ and $S_{j, t}$ for $t=N-L_{j}+1, \ldots, N-1$ cannot be calculated from $\left\{X_{t}: t=0, \ldots, N-1\right\}$ since they require the knowledge of $X_{t}$ for at least some $t>N-1$.

Similarly to Section 5.1, some boundary conditions can be introduced which would provide surrogates for $X_{t}$ for $t<0$ and $t>N-1$, thus enabling the surrogates for $D_{j, t}$ and $S_{j, t}$ to be obtained for $t=0, \ldots, L_{j}-2$ and $t=N-L_{j}+1, \ldots, N-1$. For example, the circularity or reflection boundary conditions discussed in Section 5.1 could be employed. Let us denote the sequences of the $j$ th-level MODWT detail and the $j$ th-level MODWT smooth calculated from $\left\{X_{t}: t=0, \ldots, N-1\right\}$ using some boundary conditions as $\left\{D_{j, t}{ }^{(b)}: t=0, \ldots, N-1\right\}$ and $\left\{S_{j, t}{ }^{(b)}: t=0, \ldots, N-1\right\}$ where the superscript $(b)$ emphasises that some values of these sequences, namely those with $t=0, \ldots, L_{j}-2$ and $t=N-L_{j}+1, \ldots, N-1$, are calculated making use of some boundary conditions denoted as $(b)$. We say that $D_{j, t}{ }^{(b)}$ and $S_{j, t}{ }^{(b)}$ for $t=0, \ldots, L_{j}-2$ and $t=N-L_{j}+1, \ldots, N-1$ are affected by the boundary conditions. Moreover, $D_{j, t}^{(b)} \neq D_{j, t}$ and $S_{j, t}^{(b)} \neq S_{j, t}$ for $t=0, \ldots, L_{j}-2$ and $t=N-L_{j}+1, \ldots, N-1$. Here, $D_{j, t}$ and $S_{j, t}$ denote the values of the detail and smooth series as defined by Equations 25 and 26 where $\left\{X_{t}: t=\ldots,-1,0,1, \ldots\right\}$ consists of the true values only and no surrogates.

Software packages tend to output sequences $\left\{D_{j, t}{ }^{(b)}: t=0, \ldots, N-1\right\}$ and

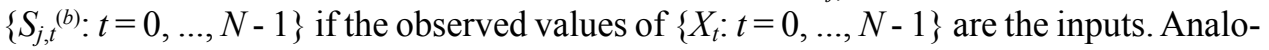
gously to the previous discussion, this may lead the researcher to mistakenly assume that all the values of $\left\{D_{j, t}{ }^{(b)}: t=0, \ldots, N-1\right\}$ and $\left\{S_{j, t}{ }^{(b)}: t=0, \ldots, N-1\right\}$ are justified for use in further analysis. However, this is not the case since $D_{j, t}{ }^{(b)}$ and $S_{j, t}{ }^{(b)}$ for $t=0, \ldots, L_{j}-2$ and $t=N-L_{j}+1, \ldots, N-1$ may generally deviate from the true (and unavailable) values of $D_{j, t}$ and $S_{j, t}$ (for $t=0, \ldots, L_{j}-2$ and $t=N-L_{j}+1, \ldots, N-1$ ), the deviation being the larger the closer $t$ is either to zero or to $N-1$. This supports the exclusion of the values of the detail and smooth series affected by the boundary conditions from further analysis if no justification for their use is given. Unfortunately, 
discarding these values from further analysis means discarding some values of $\left\{D_{j, t}{ }^{(b)}: t=0, \ldots, N-1\right\}$ and $\left\{S_{j, t^{(b)}}: t=0, \ldots, N-1\right\}$ not only at the left tail but also at the right tail of these sequences.

In the top plot of Figure 7, the same plot is presented as was depicted in the top plot of Figure 4. Hence, see Section 5.1 for the description of the plot and the explanation of the boundary conditions illustrated in the plot. In the second, third, fourth and fifth plots from the top of Figure 7 the first-level, $\left\{D_{1, t}{ }^{(b)}: t=0, \ldots, 9\right\}$, second-level, $\left\{D_{2, t}{ }^{(b)}: t=0, \ldots, 9\right\}$, and third-level Haar detail, $\left\{D_{3, t}{ }^{(b)}: t=0, \ldots, 9\right\}$, together with the third-level Haar smooth, $\left\{S_{3, t}{ }^{(b)}: t=0, \ldots, 9\right\}$, are presented. The values of the detail and smooth sequences affected by the boundary conditions are to the left of the dotted vertical lines or to the right of the dashed vertical lines. Similarly to Section 5.1, three sets of these values affected by the boundary conditions are shown.

- The first set, denoted with empty circles (to the left of the vertical dotted lines or to the right of the vertical dashed lines), corresponds to the situation where only the true values of $X_{t}$ from the shaded region of the top plot are used in the calculation of the values of the details and smooth.

- The second set is represented by filled circles (to the left of the vertical dotted lines or to the right of the vertical dashed lines) and corresponds to the case where the circularity boundary conditions (marked with filled circles in the top plot of the figure) are used for calculating the values of the details and smooth.

- The third set is depicted by crosses (to the left of the vertical dotted lines or to the right of the vertical dashed lines) and corresponds to the situation where the reflection boundary conditions (marked with crosses in the top plot of the figure) are used for determining the values of the details and smooth.

We see that all values are affected by the boundary conditions in the series of the third level detail or third level smooth.

Whatever boundary conditions we employ, it always holds that

$$
\sum_{j=1}^{3} D_{j, t}^{(b)}+S_{3, t}^{(b)}=X_{t}, \quad t=0, \ldots, 9 .
$$

Despite this fact, Figure 7 clearly reveals that the dynamics of the parts of the detail and the smooth sequences affected by the circularity or reflection boundary conditions is not the same as the dynamics would be if the true values of the input time series were known and used. 


\section{Figure 7}

Illustration of the impact of circularity (filled circles) and reflection (crosses) boundary conditions on the time series of Haar details and smooth. See the text for a description.
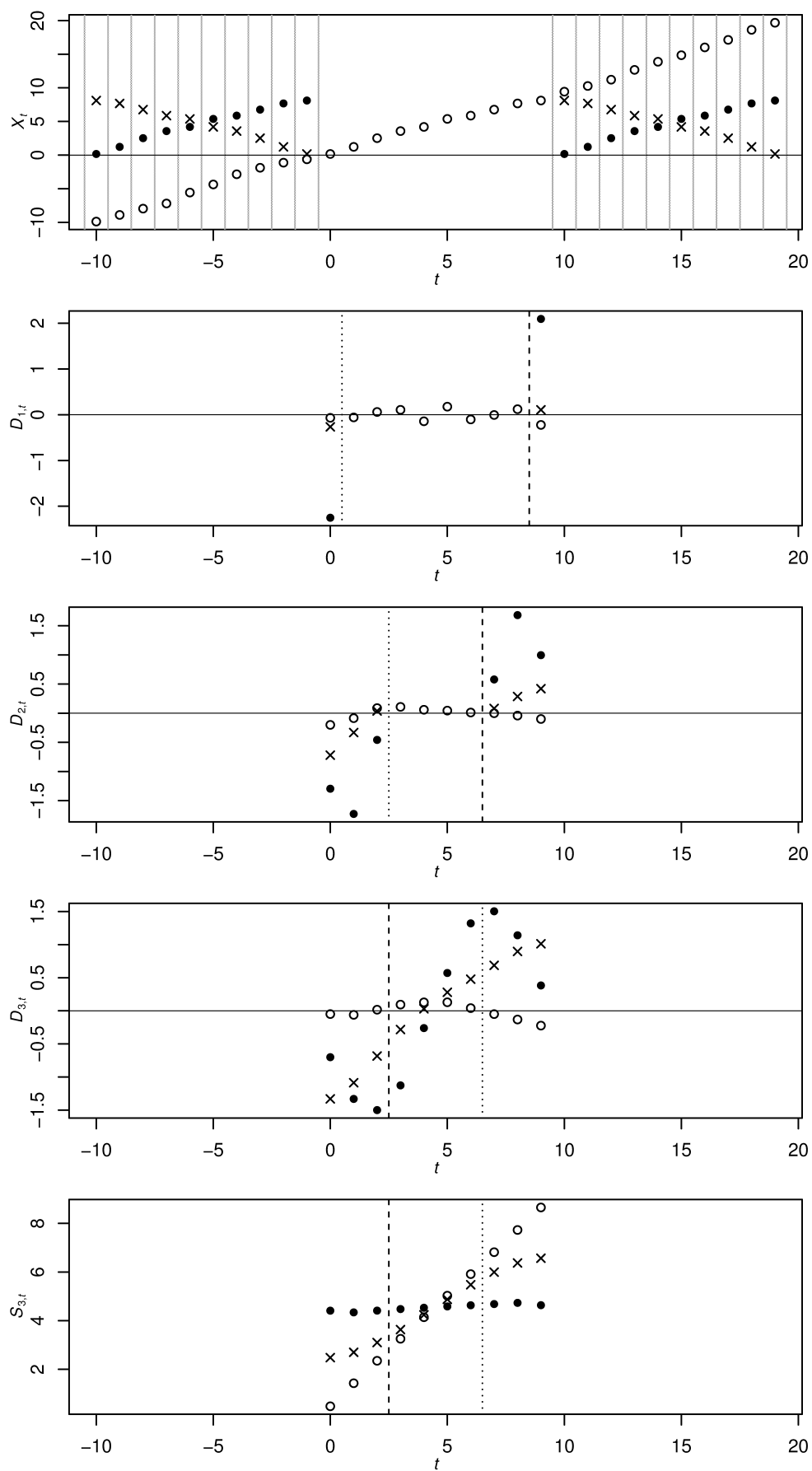


\subsection{Forecasting}

Appealing to the additive decomposition of Equation 31, which is true for general filters, we could additively decompose the input time series into details and smooth as a part of the wavelet-based forecasting approach outlined in Section 1. Since the details and the smooth are obtained by filtering the input time series with non-causal linear filters, some boundary conditions must be introduced to get the values of the detail and smooth sequences at the left as well as the right tails. Even though the additive decomposition of Equation 31 is still valid even if we employ circularity, reflection or other "ad hoc" boundary conditions, the dynamics of the portions of the detail and the smooth sequences affected by these boundary conditions does not match the dynamics of the portions not affected by the boundary conditions (see Section 7.1).

Such a situation is unfortunate from the classical modelling point of view since we would prefer only one data-generating process which generates the realisation of the entire detail/smooth sequence. If this was the case, building the model for the dynamics of the detail/smooth, estimation of the model parameters and extrapolation (forecast) of the detail/smooth sequences would be more straightforward, employing the usual approaches used in time series modelling and forecasting. This fact does not seem to have always been correctly understood in the literature (see Section 2), where, e.g., the same ARIMA model is (wrongly) assumed to govern the behaviour of both the portions of the detail/smooth sequences affected and those unaffected by the boundary conditions.

In contrast to the forecasting approach introduced in Section 5, the exclusion of the data affected by the boundary conditions is not a good solution since both the left and the right tails of the detail/smooth sequences are affected by the boundary conditions because of the non-causality of the linear filters used in their calculation. However, if we introduce the boundary conditions in a more realistic way, we may get a better forecasting performance. More specifically, being inspired by the U.S. Census Bureau and its X-12-ARIMA decomposition, we could forecast the future values of the time series $\left\{X_{t}: t=0, \ldots, N-1\right\}$ and use these forecasts as the boundary conditions. Afterwards, the details and the smooth would be calculated using these boundary conditions, modelled and forecasted, the forecasts summed up, the sum providing new forecasts of $\left\{X_{t}: t=0, \ldots, N-1\right\}$. We could repeat this "forecast-decompose" cycle several times. Such an idea has been proposed, e.g., by Yu et al. (2001). The algorithm - designed for forecasting the input time series one step ahead (multiple-step-ahead forecast generalisation might easily follow, though) - is given as follows:

- Step 1: Forecast the input time series $\left\{X_{t}: t=0, \ldots, N-1\right\}$ one through $L_{J}-1$ steps ahead. To get these forecasts, use, for example, any classical model, estimate the model parameters using the available data, $\left\{X_{t}: t=0, \ldots, N-1\right\}$, and forecast the time series. Denote the one- through $\left(L_{J}-1\right)$-step-ahead forecasts as $\hat{X}_{N}, \ldots, \hat{X}_{N-L_{J}-2}$. 
- Step 2: Append the time series $\left\{X_{t}: t=0, \ldots, N-1\right\}$ with the forecasted values $\hat{X}_{N}, \ldots, \hat{X}_{N-L_{J}-2}$, forming a new sequence

$$
\left\{X_{t}^{(0)}: t=0, \ldots, N+L_{J}-2\right\} \equiv\left\{X_{0}, \ldots, X_{N-1}, \hat{X}_{N}, \ldots, \hat{X}_{N+L_{J}-2}\right\}
$$

of the total length $N+L_{J}-1$.

- Step 3: Using the sequence $\left\{X_{t}^{(0)}: t=0, \ldots, N+L_{J}-2\right\}$ constructed in step 2, define $\left\{D_{j, t}{ }^{(0)}: t=L_{j}-1, \ldots, N-1\right\}$ (for $\left.j=1, \ldots, J\right)$ and $\left\{S_{J, t}{ }^{(0)}: t=L_{J}-1, \ldots, N-1\right\}$ as follows (see Equations 25 and 26):

$$
\begin{gathered}
D_{j, t}^{(0)} \equiv \sum_{l=-\left(L_{j}-1\right)}^{L_{j}-1} d_{j, l} X_{t-l}^{(0)}, \quad \text { for } t=L_{j}-1, \ldots, N-1, \\
S_{J, t}^{(0)} \equiv \sum_{l=-\left(L_{J}-1\right)}^{L_{J}-1} s_{J, l} X_{t-l}^{(0)}, \quad \text { for } t=L_{J}-1, \ldots, N-1 .
\end{gathered}
$$

- Step 4: Propose and estimate a suitable model for $\left\{D_{j, t}{ }^{(0)}: t=L_{j}-1, \ldots, N-1\right\}$ and $\left\{S_{J, t}^{(0)}: t=L_{J}-1, \ldots, N-1\right\}$. Use the estimated models to obtain the forecasts of $D_{j, N-1+i}^{(0)}$ and $S_{J, N-1+i}^{(0)}$, for $i=1, \ldots, L_{J}-1$. These forecasts are denoted as $\hat{D}_{j, N-1+i}^{(0)}$ and $\hat{S}_{J, N-1+i}^{(0)}$ and should be attempted to be as close as possible to optimal forecasts (in the mean square error sense).

- Step 5: Form a new forecast of $X_{N-1+i}$, for $i=1, \ldots, L_{J}-1$, denoted as $\hat{X}_{N-1+i}$, as follows:

$$
\hat{X}_{N-1+i} \equiv \sum_{j=1}^{J} \hat{D}_{j, N-1+i}^{(0)}+\hat{S}_{J, N-1+i}^{(0)}
$$

- Step 6: Now, repeat steps 2 through 5 with $\hat{X}_{N}, \ldots, \hat{X}_{N-L_{J}-2}$ of step 2 taken to be the $\hat{X}_{N}, \ldots, \hat{X}_{N-L_{J}-2}$ obtained in step 5 of the current cycle. The iteration should be stopped if a termination criterion is met, such as reaching the maximum number of cycles.

- Step 7: When the iteration is finished, take $\hat{X}_{N}$ as a forecast of the future value $X_{N}$. 


\section{Discussion and conclusions}

Decomposing input time series into several band-pass components, forecasting each component separately and summing up individual forecasts to form the prediction of the input time series can be implemented making use of the wavelet transform. In this paper, we have explained that there are two simple approaches to forecasting based on the maximum overlap discrete wavelet transform (MODWT).

Firstly, it is possible to decompose input time series into several series of Haar MODWT wavelet and scaling coefficients, forecast each of these series separately and sum up the forecasts. Since the Haar MODWT wavelet and scaling filters are causal, only the left tail of the series of MODWT coefficients is affected by the boundary conditions, and no boundary problems have to be tackled at the right tail. In contrast to Haar filters, a similar approach to forecasting is generally not possible for other types of filters.

Secondly, it is possible to decompose input time series into MODWT details and smooth and forecast each of these sequences separately, summing up the predictions to construct an overall forecast. While the decomposition step can be implemented with any type of filters, the overall approach suffers from the fact that the left as well as the right tails of the detail and smooth sequences are affected by the boundary conditions since the corresponding linear filters are non-causal. A simple solution to this problem is suggested, e.g., by Yu et al. (2001), consisting of an iterative approach where reasonable boundary conditions are used rather than "ad hoc" ones.

Apart from the MODWT, there are other types of wavelet transforms such as the discrete wavelet transform (DWT) and the continuous wavelet transform (CWT). An additive decomposition of input time series using DWT coefficients is impossible (even for Haar filters) due to the way in which the DWT coefficients are constructed (among other things, they are subsampled). However, the input time series can be additively decomposed into DWT details and smooth. These are the DWT counterparts of MODWT details and smooth. Similarly to MODWT details and smooth, the DWT details and smooth are affected by the boundary conditions at their left as well as right tails. However, unlike the MODWT details and smooth, the DWT details and smooth generally suffer from artefacts not related to the true series but rather to the algebraic nature of the DWT transform (see, e.g., Percival and Walden, 2002). Furthermore, the DWT details and smooth can change substantially by appending new data points to the left tail of the input time series. We conclude that the DWT is not attractive for forecasting the time series by decomposing it into band-pass sequences, predicting each sequence separately and summing up the forecasts.

Likewise, the CWT is also unfavourable for these purposes. Unlike the MODWT coefficients, which capture the dynamics of input time series at different, approximately non-overlapping frequency bands, the CWT coefficients are highly redundant in this aspect, providing "overlapping" information in the frequency domain. This is not an appealing feature for our purpose since the decomposition into "non-overlapping" information in the frequency domain is preferred for being closer to the concept of classical time series decomposition. 


\section{Acknowledgment}

This paper was written at the Faculty of Informatics and Statistics, University of Economics in Prague, Czech Republic and was supported by the Czech Science Foundation (GA CR), grant no. P402/12/P507, Modelling of Financial and Economic Time Series - Application and Comparison of Wavelet and Traditional Methods. We acknowledge the comments of the reviewers which helped to improve the paper. We also acknowledge the linguistic assistance of Karel Helman, Sr (Private University College of Economic Studies Ltd., Prague).

\section{References}

CONEJO, A.; PLAZAS, M.; ESPINOLA, R.; MOLINA, A. Day-Ahead Electricity Price Forecasting Using the Wavelet Transform and ARIMA models. IEEE Transactions on Power Systems. 2005, vol. 20, p. 1035-1042.

CONSTANTINE, W.; PERCIVAL, D. wmtsa: Wavelet Methods for Time Series Analysis. $R$ package, version 1.1-1, 2012, http://cran.r-project.org/package=wmtsa.

CORNISH, C. R.; BRETHERTON, C. S.; PERCIVAL, D. B. Maximal Overlap Wavelet Statistical Analysis with Application to Atmospheric Turbulence. Boundary-Layer Meteorology. 2006, vol. 119, p. 339-374.

GRINSTED, A.; MOORE, J. C.; JEVREJEVA, S. Application of the Cross Wavelet Transform and Wavelet Coherence to Geophysical Time Series. Nonlinear Processes in Geophysics. 2004, vol. 11, p. 561-566.

PERCIVAL, D. B.; WALDEN, A. T. Wavelet Methods for Time Series Analysis. (reprint). Cambridge University Press, 2002. ISBN 9780521640687.

R CORE TEAM. R: A language and environment for statistical computing. R Foundation for Statistical Computing, 2013, Vienna, Austria, http://www.R-project.org.

RAMSEY, J. B.; ZHANG, Z. The Analysis of Foreign Exchange Data Using Waveform Dictionaries. Journal of Empirical Finance. 1997, vol. 4, p. 341-372.

RENAUD, O.; STARCK, J. L.; MURTAGH, F.: Wavelet-based combined signal filtering and prediction. IEEE Transactions on Systems, Man and Cybernetics, Part B: Cybernetics. 2005, vol. 35, p. 1241-1251.

SOLTANI, S. On the use of the wavelet decomposition for time series prediction. Neurocomputing. 2002, vol. 48., p. 267-277.

WONG, H.; IP, W. C.; XIE, Z.; LUI, X. Modelling and forecasting by wavelets, and the application to exchange rates. Journal of Applied Statistics. 2003, vol. 30, p. 537-553.

YOUSEFI, S.; WEINREICH, I.; REINARZ, D. Wavelet-based prediction of oil prices. Chaos, Solitons \& Fractals. 2005, vol. 25, p. 265-275.

YU, P.; GOLDENBERG, A.; BI, Z. Time series forecasting using wavelets with predictor-corrector boundary treatment. In 7th ACM SIGKDD International Conference on Knowledge Discovery and Data Mining, 2001. 


\title{
ADDITIVE DECOMPOSITION AND BOUNDARY CONDITIONS IN WAVELET-BASED FORECASTING APPROACHES
}

\begin{abstract}
An interesting approach to economic and financial time series forecasting consists of decomposing an input time series additively into several components, each component capturing the dynamics of a different frequency range. Consequently, each component is modelled and forecasted separately, the predictions being summed up to form an overall forecast of the input time series. The present paper considers one very important aspect of the forecasting procedure. More specifically, it provides a better understanding of how an additive decomposition of the input time series into several components can be obtained using the wavelet transform and how boundary conditions in the individual components should be properly treated. Even though these aspects are presented as a part of the wavelet theory in several books on wavelets, their implementation is prone to misinterpretations in the literature on applied time series forecasting, possibly due to the complexity of the wavelet transform. Since our exposition is focused predominantly on these aspects, it provides a concise explanation which may be helpful to practitioners. The maximal overlap discrete wavelet transform is employed, other types of wavelet transforms also being briefly discussed.
\end{abstract}

Keywords: time series, wavelets, forecasting, decomposition, finance

JEL Classification: C49, C53, C32

TYLL, L. Podniková strategie. Praha : C. H. Beck, 2014. 276 s. ISBN 978-80-7400-507-7.

Současná ekonomická situace nutí manažery a vlastníky podniků v ještě větší míře hledat varianty, jak udržet svou firmu na trhu. Toto úsilí je často realizováno prostřednictvím krátkodobých až střednědobých cílů, u nichž je patrná snaha o maximální efektivitu a hospodárnost provozu. Této snaze nelze v podstatě nic upřít, pokud je součástí dlouhodobé růstové vize celého podniku. Právě vizi a snahu o budoucí rozvoj podniku však v současné době u mnohých manažerů postrádáme. Cílem publikace je proto nabídnout pohled na možnosti dlouhodobého rozvoje firmy. Na př́kladu řady reálných firem je ukázáno, že to, co odlišuje dobré firmy od těch horších, je jejich dlouhodobá strategie, která se vedle provozní stránky zaměřuje především na inovace, internacionalizaci a spolupráci s ostatními subjekty na trhu. $\mathrm{V}$ dnešní době nelze hledat konkurenční výhodu firmy pouze $\mathrm{v}$ jejím nitru, ale především ve schopnosti užší integrace se svým okolím.

Text publikace je rozdělen do 10 kapitol: Podniková strategie, Vnější okolí podniku, Vnitřní zdroje podniku, Konkurenční strategie, Celopodniková strategie a život podniku, Strategie internacionalizace podnikových činností, Inovační strategie, Fúze, akvizice a strategické aliance, Firemní kultura, etika v podnikání a společenská odpovědnost firmy, Volba strategie a měření její efektivity. Jednotlivé kapitoly provedou čtenáře celým procesem tvorby podnikové strategie od analýzy vnějšího a vnitřního prostředí, přes návrh strategických variant až po konečné hodnocení a výběr té nejlepší budoucí cesty. 